\title{
Addition of L-Cysteine and Vitamin E to Semen Diluent Enhances Freeze-thawed Spermatozoa Characteristics in Crossbred Cattle Bulls under Subtropical Environment
}

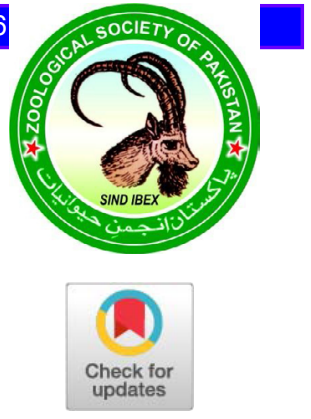

\author{
Ibrar Muhammad Khan ${ }^{1}$, Dezhi Xu' ${ }^{1}$ Zubing Cao ${ }^{1}$, Hongyu Liu', Adnan Khan', \\ Sajid Ur Rahman ${ }^{3}$, Jam Zaheer Ahmed ${ }^{4}$, Muhammad Akmal Raheem ${ }^{5}$ and Yunhai Zhang ${ }^{1 *}$ \\ ${ }^{1}$ Anhui Provincial Laboratory of Local Livestock and Poultry Genetical Resource \\ Conservation and Breeding, College of Animal Science and Technology, Anhui \\ Agricultural University, Hefei, Anhui, China, 230036
}

${ }^{2}$ Department of Animal Genetics, Breeding and Reproduction College of Animal Science and Technology, China Agricultural University, Beijing, China

${ }^{3}$ Key Laboratory of Animal Parasitology of Ministry of Agriculture, Laboratory of Quality and Safety Risk Assessment for Animal Products on Biohazards (Shanghai) of Ministry of Agricultural Sciences, Shanghai Veterinary Research Institute, Chinese Academy of Agricultural Sciences, Shanghai 200241, China

${ }^{4}$ State Key Laboratory for Conservation and Utilization of Subtropical AgroBioresources, Guangxi University, Nanning, Guangxi, China ${ }^{5}$ Key Laboratory of Veterinary Pathobiology and Disease Control, College of Animal Science and Technology, Anhui Agricultural University, Hefei, China

\begin{abstract}
A B S T R A C T
Vitamins and amino acids are important trace nutrients that are essential for body growth and reproductive soundness, whereas the lack of these nutrients is directly related to reproductive performance. Hence, the antioxidants agents (L-cysteine and vitamin E) were added into semen diluent and assessed the freezethawed semen quality parameters. The ejaculates were collected from two crossbred groups (Sahiwal $\times$ Holstein-Friesian), and (Achai $\times$ Jersey) and, split into seven aliquots while extended with three different concentration $(5,7.5$ and $10 \mathrm{mmol})$ of L-cysteine diluents and followed by other three concentrations (1.2, 2.4 and $4.8 \mathrm{mmol}$ ) of vitamin E diluents and, the last aliquot of semen was extended with control (no additives) to semen diluent. The spermatozoa freeze-thawed quality were assessed and found that total motility, progressive motility, membrane functionality, acrosomal integrity, and viability percentage were significantly higher $(P<0.05)$ in the diluent groups treated with $7.5 \mathrm{mmol}$ of L-cysteine or $4.8 \mathrm{mmol}$ of vitamin E. Correspondingly the DNA integrity and mitochondrial membrane potential percentage were found significantly higher $(P<0.05)$ in diluent groups treated with $7.5 \mathrm{mmol}$ L-cysteine or 4.8 $\mathrm{mmol}$ vitamin $\mathrm{E}$. The juvenile results indicated that L-cysteine and vitamin $\mathrm{E}$ improves the freeze-thawed spermatozoa characteristics in crossbred bulls.
\end{abstract}

\begin{tabular}{l} 
Article Information \\
\hline Received 06 October 2019 \\
Revised 29 December 2019 \\
Accepted 28 January 2020 \\
Available online 14 May 2021 \\
Authors' Contribution \\
IMK and YZ presented the concept \\
of the study. IMK and AK processed \\
the data. SUR, JZA and DX analysed \\
the data. YZ, ZC and HL did funding \\
acquisition. IMK and MAR defined \\
methodology. YZ administrated \\
the project. SUR provided technical \\
support. ZC and IMK wrote the \\
manuscript. \\
Key words \\
Crossbred bulls, Cryopreservation, \\
Freeze-thawed semen, L-cysteine, \\
Vitamin E
\end{tabular}

\section{INTRODUCTION}

$\mathrm{T}$ he idea behind cross breeding is to generate crossbred offspring with early maturity, superior dairy characteristics and adaptability to harsh local environmental condition. However, little attention has been devoted to improving the quality of breeding programs (Sattar and Mirza, 2009). Over 50\% of crossbred juvenile bulls used for semen collection were reported to have complications related to the quality of semen, cryo-biology and libido

\footnotetext{
Corresponding author: yunhaizhang@ahau.edu.cn 0030-9923/2021/0004-1309 \$ 9.00/0

Copyright 2021 Zoological Society of Pakistan
}

(Mukhopadhyay et al., 2010; Mandal and Tyagi, 2004). Compared to crossbred bulls, indigenous or purebred bulls were reported to have sperm with higher freezing ability and fertility. Due to poor (initial) semen quality nearly $50 \%$ to $55 \%$ of ejaculates collected from crossbred bulls were inappropriate for freezing (Sudheer and Xavier, 2000). Various efforts have been made to determine the etiology of poor quality semen production in crossbred bulls in the seminological, andrological, genetical and probable an ecological stage with varied success (Gulia et al., 2010; Mandal et al., 2008). Crossbred progeny have been reported to be more prone to reproductive problems than purebred offspring (Bitew and Prasad, 2011). One important factor of sub-fertility in cattle production is the 
use of substandard semen in artificial insemination (AI) (Gnoth et al., 2005). Sub-fertility may occur as a result of disorders in semen production including reduced or loss of sperm motility (Dirami et al., 2013).

Cryopreservation is the key technique for artificial insemination and providing a platform to distribute the elite genetic material worldwide but the freezing-thawing cycle can have detrimental effect on sperm biology, causing damage and modifications that eventually lead to the death of sperm cell, thereby reducing fertility (Trachootham et al., 2009). Cryopreservation can generate reactive oxygen species (ROS) which interact with sperm cell plasma membrane leading to trans-omics disturbance and suffer the fertility. When ROS exceed the normal level and spermatozoa defence mechanisms are decreased not only the plasma structure but also DNA can be damaged. This damage can reduce spermatozoa fertility and the capability to develop a healthy embryo (Pons-Rejraji et al., 2009). Another study found that low ROS production is positively correlated with spermatozoa motility whereas high ROS production was negatively correlated with sperm motility. This ROS-induced decline in spermatozoa motility, is primarily attributed to decreased ATP production (Armstrong et al., 1999).

Previous studies have found that the antioxidant property of vitamin $\mathrm{E}$ can improve the freeze-thawed traits of spermatozoa and contribute to the management of male infertility (Keskes-Ammar et al., 2003). Vitamin E and beta-carotene have been shown to have the antioxidant property that support cells against ROS damage (Almbro et al., 2011). Vitamin $\mathrm{E}$ is considered to be the most active agent in the antioxidant system of spermatozoa, where it protects the cell membrane against attack from ROS and lipid peroxidation (LPO) (Yousef et al., 2003). The administration of antioxidant agents to semen diluent has been improving the indicators of spermatozoa motion (e.g. spermatozoa longevity, individual motility, progressive motility and viability) in Ghezel rams (Aminipour et al., 2013). However, cattle bull semen has natural guard system against the ROS and, that are considered insufficient, when the spermatozoa going through the critical phase of freezethawed imposed stress (Nichi et al., 2006).

Therefore, it is essential to strengthen the semen diluent with appropriate antioxidant supplements to reduce ROS damages durring the freeze-thawing of bull semen. Cysteine is another active agent, also known to act as an intracellular antioxidant and guard's cells against oxidative stress and damage (Meister and Anderssson, 1983). L-cysteine comprises an important thiol group that works as a non-enzymatic antioxidant and easily penetrates into sperm cells. The addition of cysteine to semen diluent has been reported to improve the freeze-thawed motility and viability of boar (Kaeoket, 2010), buck (Kulaksiz and Daskin, 2010) and bull semen (Sariözkan et al., 2009).

This study assessed the effect of L-cysteine and vitamin $E$ administration to semen diluent on freeze-thawed spermatozoa characteristics. The ideal concentrations of antioxidant supplements for the cryopreservation media of crossbred bull semen was also determined that resulting in the good post-thawed semen characteristics. We perceived that addition of L-cysteine and vitamin $\mathrm{E}$ to semen diluent would improve the freeze-thawed semen qualities (e.g., spermatozoa motility, membrane functionality, acrosomal integrity, DNA integrity, and spermatozoa viability ratio and mitochondrial membrane potential) of crossbred bull.

\section{MATERIALS AND METHODS}

Animals and rearing system

Six physically and andrologically healthy mature bulls of two crossbred groups, (Sahiwal $\times$ Holstein-Friesian) and $($ Achai $\times$ Jersey), were selected from the National Agriculture Research Center (NARC) in Islamabad. The average age of the bulls were $3.0 \pm 0.14$ years. All experimental bulls were reared under the same feeding regime and housing facilities. Seasonal green fodder $a d-$ libitum and formulated feed (e.g., maize gluten 30 of $15 \%$, cotton seed cake $18 \%$, maize grain broken $14 \%$, canola meal $10 \%$, molasses $16 \%$, wheat bran $25 \%$, and mineral mixture $2 \%$ ) were being offered.

\section{Semen collection}

According to standard artificial insemination procedure, total of sixteen ejaculates were collected from each bull. The following criteria were considered for collected ejaculates: volume of $2-6 \mathrm{~mL}$, concentration $\geq$ $60 \times 10^{6}$ spermatozoa $\mathrm{mL}^{-1}$ and total motility of $70 \%$ for conducting the post-thaw experiments (Tuncer et al., 2010). The volume of collected semen was measured while using a graduated tube and the initial spermatozoa total motility was determined microscopically (magnification 400X; Olympus BX20, Tokyo, Japan). The fresh spermatozoa concentration was evaluated using a digital photometer (L'Aiglon; IMV, Cedex, France) and pooled ejaculates were used for further assessment.

\section{Addition of L-cystiene and vitamin $E$ in semen diluent}

The stock diluent comprised of $1.56 \%$ citric acid (Fisher Scientific, UK), 3.0\% tris-(hydroxymethyl)aminomethane (Research Organics, USA), 0.2\% glucose (Scharlau, Spain), 7\% glycerol (Riedel-deHaen, Germany), $20 \%$ egg yolk in distilled water, at $\mathrm{pH} 6.8$ and standard osmotic pressure of $320 \mathrm{mOsmol} \mathrm{kg-1} \mathrm{for} \mathrm{cattle} \mathrm{bulls} \mathrm{was}$ used (Beheshti et al., 2011). The semen samples $60 \times 10^{6}$ 
spermatozoa / $\mathrm{mL}$ concentration were used for dilution and then divided into seven different experimental fractions. The $1 \mathrm{st}, 2^{\text {nd }}$ and $3^{\text {rd }}$ fractions were diluted containing Cysteine (C8786; Sigma-Aldrich Co., St. Louis, MO, USA) at concentrations of $5 \mathrm{mmol}$ (L-cysteine-1), $7.5 \mathrm{mmol}$ (L-cysteine-2) and $10 \mathrm{mmol}$ (L-cysteine-3); the $4^{\text {th }}, 5^{\text {th }}$ and $6^{\text {th }}$ fractions were diluted containing Vitamin E (SigmaAldrich Co., St. Louis, MO, USA) at concentrations of $1.2 \mathrm{mmol}$ (vitamin-E-1), $2.4 \mathrm{mmol}$ (vitamin-E-2) and 4.8 mmol (vitamin-E-3) whereas the 7th (control fraction) was without any addition of additives to the diluent. Vitamin $\mathrm{E}$ was dissolved in absolute ethanol of $(0.05 \% \mathrm{v} / \mathrm{v})$ to prepare a stock solution of $10 \mathrm{mM}$ before it was added to the diluent (Motemani et al., 2017).

\section{Cryopreservation}

All diluted samples were cooled at $4{ }^{\circ} \mathrm{C}$ over $2 \mathrm{~h}$ in cooled cabinet and after cooling the samples were exposed to equilibration time (e.g., total refrigeration time $4 \mathrm{~h}$ at $4{ }^{\circ} \mathrm{C}$ ) (Leite et al., 2010). At the end of cooling and equilibration period the extended samples were added to $0.25 \mathrm{~mL}$ French straws and sealed with a filling and sealing device (IMV, L'Aigle, France). The semen straws were cryo-preserved through programmable bio-freezer (Minitub, Tiefenbach, Germany) at $-20^{\circ} \mathrm{C} / \mathrm{min}$ to $-100^{\circ} \mathrm{C}$ and at $-10^{\circ} \mathrm{C} / \mathrm{min}$ from $-100^{\circ} \mathrm{C}$ to $-140^{\circ} \mathrm{C}$ and finally plunged into liquid nitrogen. After a week, the frozen straws were thawed for freeze-thawed assessment.

\section{Post-thawed semen evaluation}

The following parameters were evaluated in the freeze-thawed semen of bulls whereas all the parameters were tested for three times consecutively.

\section{Spermatozoa total motility and progressive motility}

The spermatozoa total motility and progressive motility parameters were assessed by computer assisted sperm motion analysis (CASA, Version 5.1; Microptic Barcelona, Spain). A total of $10 \mu \mathrm{L}$ of freeze-thawed semen was placed in pre-warmed Makler chamber (Sperm Meter; Sperm Processor Pvt. Ltd, Aurangabad, India) and examined. We randomly selected three microscopic fields each scanned five times. The mean of these fifteen scans was used for spermatozoa motility analysis.

\section{Spermatozoa membrane functionality (Hypo-osmotic} swelling test)

Spermatozoa plasma membrane functionality was determined via hypo-osmotic swelling tests (Pons-Rejraji et al., 2009). A total of $0.1 \mathrm{~mL}$ freeze-thawed semen was mixed with $1 \mathrm{~mL}$ HOST solution consisting of 0.5 mL D-fructose $(1.47 \%)$, sodium citrate $(2.7 \%)$ and eosin
$0.5 \%(\mathrm{w} / \mathrm{v})$. Following incubation at $37^{\circ} \mathrm{C}$ for $40 \mathrm{~min}, 5$ $\mu \mathrm{L}$ of sample was removed with micropipette, transferred to a pre-warmed glass slide while covered with cover slip and placed under the compound microscope at $40 \mathrm{X}$ for observation. A total of 200 spermatozoa were counted in five different fields for each sample. The HOST solution provided hypotonic media for the spermatozoa, resulting in coiled and swollen tails due to the different osmotic potential. Intact plasma membrane functionality was indicated by swollen, coiled tails and unstained heads, whereas un-swollen, uncoiled tails, and pink heads indicated disruptive spermatozoa membrane functionality.

\section{Spermatozoa viability}

To determine the ratio of viable spermatozoa, eosin (1\%) and nigrosin (5\%) stain was mixed in 3\% sodium citrate dehydrates solution. Nigrosin stain provides a background for spermatozoa visualization while eosin enters into the dead spermatozoa membrane and produces a pink color, allowed dead spermatozoa identification. A small drop of freeze-thawed semen was placed on clean pre-warmed slide. A comparatively large drop of stain was added and mixed for $30 \mathrm{~s}$ using an applicator stick. A thin smear was then made and air dried for 1 to $3 \mathrm{~min}$. After drying, the slide was observed under the compound microscope at 100X. The spermatozoa with unstained heads were considered live while those with stained or partially stained heads were considered dead. For each sample, the percentage of spermatozoa viability was calculated based on a total of 200 spermatozoa counted in 5 different microscopic fields.

\section{Spermatozoa acrosomal integrity}

Trypan-blue and giemsa staining were conducted for spermatozoa acrosomal integrity in bull (Kovacs and Foote, 1992). In this protocol, trypan-blue was used to differentiate live and dead sperms, and giemsa stain was used to evaluate sperm acrosomal integrity. One drop of trypan-blue $(2.0 \%)$ was mixed with one drop of freezethawed semen on a clean pre-warmed slide and mixed using the edge of a clean cover slip. After drying in air, the slide was fixated with formaldehyde-neutral red solution [86 mL IM HCl + 14 mL formaldehyde (Merck, Darmstadt, Germany) + 0.2g neutral red (MP Biomedicals, Eschwege, Germany)] for $5 \mathrm{~min}$. Subsequently the slide was washed with distilled water and dipped in (7.5) giemsa stain (MP Biomedicals, Eschwege, Germany) for $4 \mathrm{~h}$. After staining with giemsa stain, the slide was again rinsed with distilled water and dried in air. After covering with cover slip, the slide was covered with Canada balsam (Merck, Darmstadt, Germany). For each smear, five different fields were evaluated under a phase-contrast microscope at $1000 \mathrm{X}$ 
(LABOMED LX400), in resulting analysis of total 200 spermatozoa. As trypan-blue stain is permeable to none viable sperm and reflect blue appearance, whilst color of viable spermatozoa with intact membrane remained unchanged. In contrast, spermatozoa with intact acrosomes are permeable to giemsa stain, which turns the acrosomal part purple (Tartaglione and Ritta, 2004).

\section{Spermatozoa DNA integrity}

TNE buffer $(200 \mu \mathrm{L})$ was mixed with $20 \mu \mathrm{L}$ of freezethawed semen at $37{ }^{\circ} \mathrm{C}$ to obtain a final concentration of $2 \times 10^{6}$ spermatozoa $/ \mathrm{mL}$. Clean glass slides were used to prepare three smears from each semen aliquot. After drying in air, the smears were dipped overnight in Carnoy's solution [methanol and glacial acetic acid (Merck, Darmstadt, Germany) in a 3:1 ratio] for fixation. The slides were then allowed to dry in air and shifted to tampon solution [ $80 \mathrm{mMol}$ citric acid (Merck, Darmstadt, Germany)] and $15 \mathrm{mmol}$ sodium phosphate (Sigma, NY, USA), $\mathrm{pH}$ 2.5) for $5 \mathrm{~min}$ in a water bath at $75^{\circ} \mathrm{C}$. After incubation in tampon solution acridine orange $(0.2 \mathrm{mg} /$ $\mathrm{mL}, \mathrm{pH}$ 2.5; Sigma, NY, USA) was applied to the slides. The slides were then covered with cover slips while they were still soaking and evaluated under fluorescent microscope (LABOMED LX400). Acridine orange is a fluorescent cationic dye with affinity for nucleic acids and permeable to sperm cells. Acridine orange interacts with single or double-strand DNA via intercalation or electrostatic attraction respectively. For each smear, five different fields were evaluated to count a total of 200 sperms. Intact sperm DNA with indicated by a green appearance while disrupted DNA appeared yellowish green to red (Evenson et al., 2002).

\section{Mitochondria membrane potential}

JC-1 is a lipophilic cationic dye and sensitive marker for mitochondrial membrane potential (MMP) (T4069; Sigma -Aldrich Co.), was used for assessment of sperm MMP. In spermatozoa with high MMP, thereby the JC-1 marker forms multiplexes, known as J-aggregates, and releases orange fluorescence, while spermatozoa with low MMP then the JC-1 leftovers in monomeric form and releases green fluorescence. The thawed ejaculate samples were centrifuged for $5 \mathrm{~min}$ at $500(\mathrm{x}) \mathrm{g}$ and supernatant fluid was then discarded. The residual spermatozoa were diluted in phosphate buffer saline at a concentration of $\left(1 \times 10^{6}\right)$ spermatozoa per $\mathrm{mL}$, afterward $1 \mathrm{~mL}$ of the suspension was stained with $1 \mu \mathrm{L}$ of JC- 1 stock solution $\left(200 \mu \mathrm{Mol}\right.$ dissolved in DMSO) and incubated at $38^{\circ} \mathrm{C}$ for $40 \mathrm{~min}$, and eventually examined by flow cytometry. Red and orange fluorescence of JC-1 dye was noticed $(530 \mathrm{~nm})$ with FL1 and $(585 \mathrm{~nm})$ FL2 detectors, correspondingly
(Minervini et al., 2013).

\section{Statistical analysis}

The obtained data were statistically analyzed using SPSS version 16, SPSS Inc., Chicago, IL, USA. The Kolmogorov Smirnov test was employed to test the normal distribution of all the collected data. The results of this study are presented as (Mean \pm SEM). The total motility, sperm viability, membrane functionality, acrosomal integrity, DNA integrity and mitochondria membrane activity percentage of freeze-thawed spermatozoa of crossbred bulls were comparing between the different experimental diluent groups using one-way analysis of variance (ANOVA). Duncan multiple range test to determine significant difference; the value of $(\mathrm{P}<0.05)$ was considered statistically significant.

\section{RESULTS AND DISCUSSION}

The impact of L-cysteine and vitamin E on freezethawed sperm motility in both of crossbred bulls are demonstrated in Table I, Figures 1 and 2. Addition of antioxidants (L-cysteine and vitamin E) to semen freezing diluent with $7.5 \mathrm{mmol}$ of L-cysteine and $4.8 \mathrm{mmol}$ of vitamin $\mathrm{E}$ improved motility of freeze-thawed spermatozoa as compared to the control group $(P<0.05)$ followed by $5 \mathrm{mmol}$ of L-cysteine and $2.4 \mathrm{mmol}$ of Vitamin E groups. Similarly, $7.5 \mathrm{mmol} \mathrm{L}$-cysteine, and $4.8 \mathrm{mmol}$ of vitamin E groups are yielded highest progressive motility and that was statistically significant as compared to control group $(P<$ 0.05 ). The study design consisted of two crossbred groups e.g. Sahiwal $\times$ Holstein-Friesian and Achai $\times$ Jersey while parallel with different concentrations of both L-cysteine and vitamin $\mathrm{E}$ supplements. Both of crossbred groups were tested under different concentrations of L-cysteine and vitamin $\mathrm{E}$ to evaluate freeze-thawed spermatozoa traits. The results showed that motility parameters of freeze-thawed spermatozoa were significantly higher $(P<$ 0.05 ) in group of L-cysteine-2 and vitamin-E-3 for both types of crossbred bulls. Spermatozoa motility is crucial to cross the female reproductive tract and hurdles around the oocyte for succeeding fertilization (Bucak et al., 2012). As formerly described, spermatozoa motility and viability are usually affected features during freezing-thawing cycle and hence, these are the crucial causes for reduced fertility (Li et al., 2010). Data about the sperm motility in our study are wholly in conformity with different studies in which addition of L-cysteine and vitamin $\mathrm{E}$ augmented motility of freeze-thawed bull (Amirat-Briand et al., 2009), ram (Bucak et al., 2009) and buck spermatozoa (Kulaksiz and Daskin, 2010). 
Table I. The effect of different treated semen diluents on freeze-thawed spermatozoa total motility, progressive motility, membrane functionality, DNA integrity, acrosomal integrity, sperm viability and MMP $(\%)$ in $($ Sahiwal $\times$ Holstein-Friesian) bulls (Mean \pm SEM).

\begin{tabular}{|c|c|c|c|c|c|c|c|}
\hline \multirow[t]{2}{*}{ Parameters } & \multirow{2}{*}{$\begin{array}{l}\text { Control } \\
\text { diluent }\end{array}$} & \multicolumn{3}{|c|}{ L-cysteine group } & \multicolumn{3}{|c|}{ Vitamin E group } \\
\hline & & L-c-1 diluent & L-c-2 diluent & L-c-3 diluent & Vit-E-1 diluent & Vit-E-2 diluent & Vit-E-3 diluent \\
\hline TM (\%) & $50.00 \pm 1.60^{c}$ & $52.80 \pm 1.44^{\mathrm{b}}$ & $60.60 \pm 1.89^{\mathrm{a}}$ & $51.12 \pm 2.20^{\mathrm{bc}}$ & $51.90 \pm 1.66^{\mathrm{bc}}$ & $53.65 \pm 1.98^{\mathrm{b}}$ & $59.40 \pm 1.44^{\mathrm{a}}$ \\
\hline $\mathrm{M}(\%)$ & $15.70 \pm 2.02^{\mathrm{c}}$ & $17.10 \pm 1.88^{\mathrm{bc}}$ & $21.77 \pm 1.67^{\mathrm{a}}$ & $15.88 \pm 2.10^{\mathrm{c}}$ & $10.43 \pm 1.550$ & $18.29 \pm 2.10^{\mathrm{b}}$ & $20.68 \pm 1.90^{\mathrm{ab}}$ \\
\hline MF (\%) & $42.29 \pm 1.63^{c}$ & $45.56 \pm 1.77^{b}$ & $54.48 \pm 1.74^{\mathrm{a}}$ & $43.82 \pm 1.62^{b c}$ & $44.38 \pm 1.43^{\mathrm{bc}}$ & $46.45 \pm 1.89^{b}$ & $53.12 \pm 1.77^{\mathrm{a}}$ \\
\hline DNAI (\%) & $92.83 \pm 1.56^{\mathrm{b}}$ & $92.20 \pm 2.24^{\mathrm{c}}$ & $96.62 \pm 1.44^{\mathrm{a}}$ & $92.72 \pm 2.45^{\mathrm{b}}$ & $93.45 \pm 1.44^{\mathrm{ab}}$ & $93.48 \pm 1.66^{\mathrm{ab}}$ & $97.77 \pm 1.85^{\mathrm{a}}$ \\
\hline AI (\%) & $40.83 \pm 1.56^{\mathrm{c}}$ & $43.41 \pm 1.60^{\mathrm{b}}$ & $54.11 \pm 2.33^{\mathrm{a}}$ & $40.15 \pm 1.45^{\mathrm{c}}$ & $41.00 \pm 1.40^{\mathrm{bc}}$ & $43.00 \pm 1.80^{\mathrm{b}}$ & $52.00 \pm 2.15^{\mathrm{ab}}$ \\
\hline MMP (\%) & $37.86 \pm 1.18^{c}$ & $42.89 \pm 2.14^{b}$ & $49.50 \pm 1.88^{\mathrm{a}}$ & $40.27 \pm 2.53^{\mathrm{bc}}$ & $41.33 \pm 1.88^{\mathrm{bc}}$ & $44.18 \pm 1.90^{\mathrm{b}}$ & $48.44 \pm 2.10^{\mathrm{ab}}$ \\
\hline SV $(\%)$ & $49.87 \pm 1.50^{\mathrm{c}}$ & $52.66 \pm 1.44^{\mathrm{b}}$ & $66.35 \pm 1.65^{\mathrm{a}}$ & $50.50 \pm 1.73^{\mathrm{bc}}$ & $50.98 \pm 1.88^{c}$ & $51.44 \pm 1.40^{\mathrm{bc}}$ & $62.66 \pm 1.60^{\mathrm{a}}$ \\
\hline
\end{tabular}

*Control diluent containing no additives of L-cysteine and vitamin E; L-c-1 diluent containing 5 mmol of L-cysteine; L-c-2 diluent containing 7.5 mmol of L-cysteine; L-c-3 diluent containing $10 \mathrm{mmol}$ of L-cysteine; Vit-E-1 diluent containing 1.2 mmol of vitamin E; Vit-E-2 diluent containing 2.4 mmol of vitamin E; Vit-E-3 diluent containing $4.8 \mathrm{mmol}$ of vitamin E; Mean values bearing different superscripts in a rows differ significantly: a, ab, b, bc, $\mathrm{c}(P$ $<0.05$ ); TM, total motility; PM, progressive motility; MF, membrane functionality; DNAI, DNA integrity; AI, acrosomal integrity; MMP, mitochondria membrane potential; SV, sperm viability.

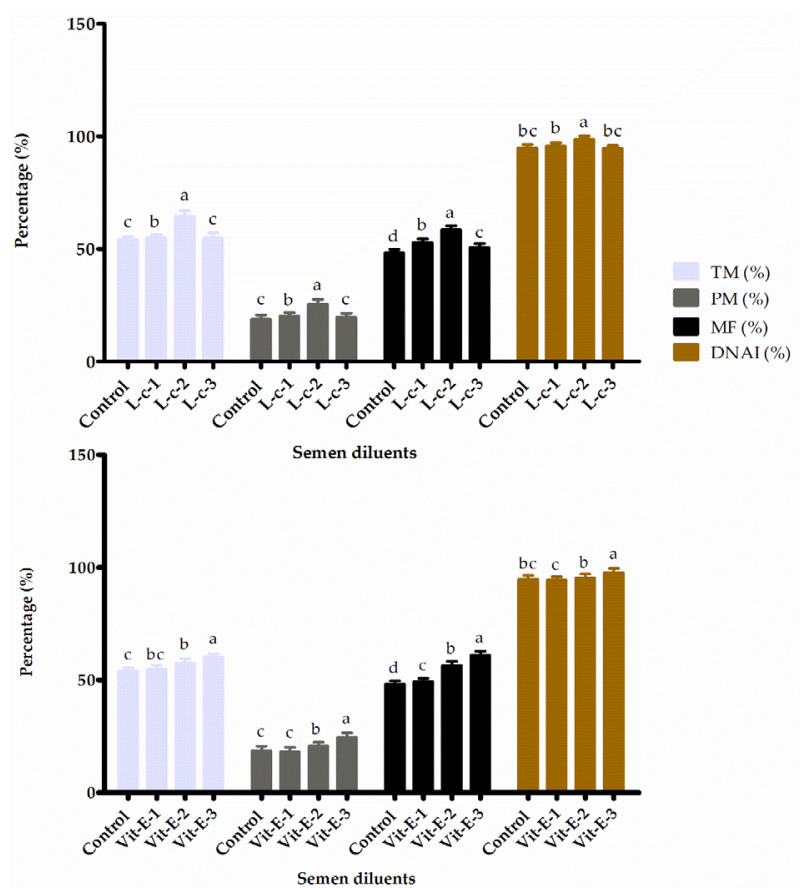

Fig. 1. The effect of L-cysteine and vitamin E supplemented diluents on freeze-thawed spermatozoa traits in Achai $x$ Jersey bulls (Mean \pm SEM). Control diluent containing no additives; L-c-1 diluent containing $5 \mathrm{mmol}$ of L-cysteine; L-c-2 diluent containing $7.5 \mathrm{mmol}$ of L-cysteine; L-c-3 containing $10 \mathrm{mmol}$ of L-cysteine; Vit-E-1 diluent containing $1.2 \mathrm{mmol}$ of vitamin E; Vit-E-2 diluent containing 2.4 mmol of vitamin E; Vit-E-3 diluent containing $4.8 \mathrm{mmol}$ of vitamin E; TM, total motility; PM, progressive motility; MF, membrane functionality; DNAI, DNA integrity; different
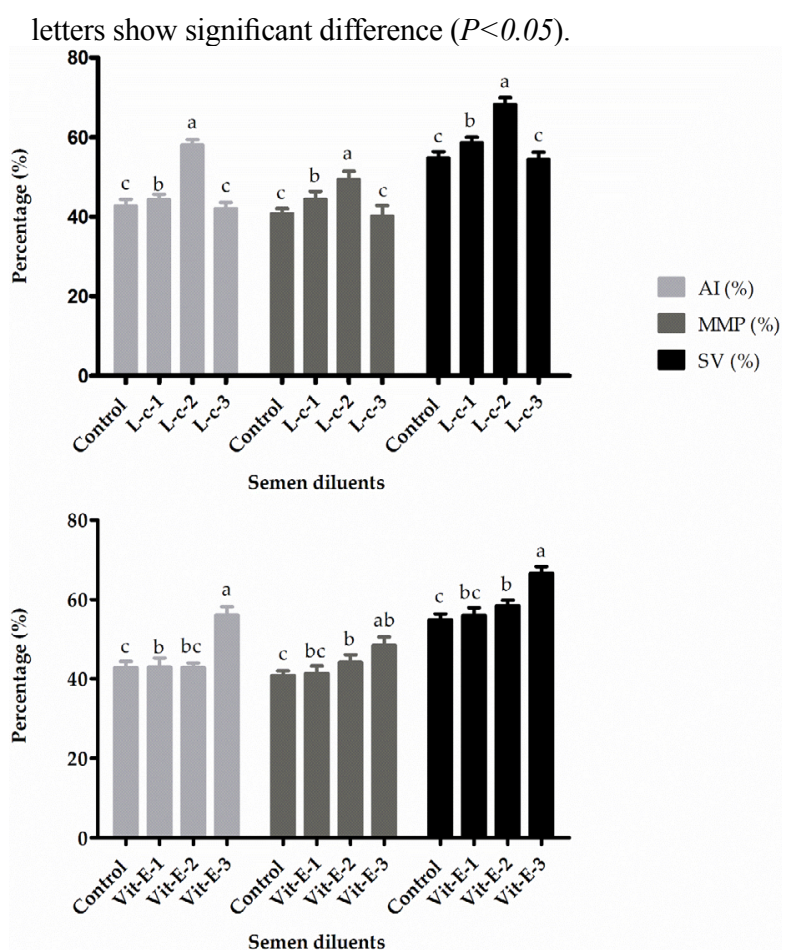

Fig. 2. The impact of L-cysteine and vitamin E supplemented diluents on freeze-thawed spermatozoa parameters in Achai $\times$ Jersey bulls (Mean \pm SEM). Control diluent containing no additives; L-c-1 diluent containing $5 \mathrm{mmol}$ of L-cysteine; L-c2 diluent containing $7.5 \mathrm{mmol}$ of L-cysteine; $\mathrm{L}-\mathrm{c}-3$ containing $10 \mathrm{mmol}$ of L-cysteine; Vit-E-1 containing $1.2 \mathrm{mmol}$ of vitamin E; Vit-E-2 containing $2.4 \mathrm{mmol}$ of vitamin E; Vit-E-3 containing $4.8 \mathrm{mmol}$ of vitamin $\mathrm{E}$. AI, acrosomal integrity; 
MMP, mitochondria membrane potential; SV, sperm viability; different letters show significant difference $(P<0.05)$.

Previous reports designated that addition of L-cysteine with concentration of 5 and $7.5 \mathrm{mmol}$ in buffalo semen freezing extender significantly improved the motility of freezethawed spermatozoa (Beheshti et al., 2011). The vitamin E is measured to be the main constituent of antioxidant system for spermatozoa (Lenzi et al., 1996). In latest studies, the supplementation of vitamin $\mathrm{E}$ into freezing diluents has been amended the freeze-thawed spermatozoa functions of ram (Silva et al., 2013), boar (Breininger et al., 2005) and tom (Thuwanut et al., 2008). Likewise, the addition of vitamin E into semen freezing extender resulting in optimistic effect on spermatozoa motility, integrity of membrane, DNA and MMP (Jeong et al., 2009).

As shown in Table $I$ and Figures 1 and 2 supplementation of crossbred bulls freezing diluent with $7.5 \mathrm{mmol}$ of L-cysteine and $4.8 \mathrm{mmol}$ of vitamin $\mathrm{E}$ are significantly improved membrane functionality of spermatozoa along with significant increase in acrosomal integrity as compared to control group $(P<0.05)$ and followed by the other groups. In this study, membrane functionality of freeze-thawed spermatozoa was significantly higher $(P<0.05)$ in groups of L-cysteine -2 and vitamin-E-3 compared with the control group. Plasma membrane is accountable for the conservation of cellular homeostasis and thereby the plasma membrane functionality applies a vital role on spermatozoa survival inside the female reproductive tract and, on conservation of spermatozoa fertilizing capability (Andrade et al., 2007). Semen collection and processing for future uses requires proper freezing methods. Spermatozoa are prone to freezing, which is altered sperm membrane activity and the degree of spermatozoa membrane damages differs based on organization, membrane permeability, fluidity and the lipid composition of sperm membrane bilayer (Motemani et al., 2017). Plasma membrane integrity in crossbred bull spermatozoa has been suggested to be significantly affected by cryopreservation compared to pure breeds (Hammerstedt et al., 1990). Lipid peroxidation (LPO) of plasma membrane disturbs membrane construction through ROS production (Thomas et al., 1998), while leading to deterioration in critical sperm properties, including membrane activity, motility and fertilization ability (Thippeswamy et al., 2014). It has been recommended that vitamin E delivers a biological stability to the spermatozoa plasma membrane while as the increase nutritional intake of vitamin E content in resulting the semen was found less prone to LPO (Surai et al., 2000; El-Sheshtawy et al., 2008). El-Sheshtawy et al. (2008) found that adding L-cysteine $(7.5 \mathrm{mmol})$ to tris-citric acid diluent increased the percent of intact membranes spermatozoa in Egyptian buffalo after cryopreservation. Likewise, treating tris-based diluent with L-cysteine $(7.5$ and $10 \mathrm{mmol})$ resulted in enhanced percentages of sperm with efficient plasma membranes in bulls (Sariözkan et al., 2009) and rams (Bucak et al., 2010), in agreement with our findings.

In this conducted research, spermatozoa acrosomal integrity in both types of crossbred bulls was significantly higher $(P<0.05)$ in groups L-c-2 and vit-E-3 compared with control group. The percentage of intact acrosomes is positively related to fertility in freeze-thawed bull spermatozoa (Hafez, 2004). The intactness of acrosomes and their enzyme (acrosin and hyaluronidase) activities are indispensable for acrosomal reaction and spermatozoaoocyte fusion (Sudheer and Xavier, 2000). The structural and functional integrity of the sperm acrosome is considered necessary to attain the high fertility however cryopreservation can damage the acrosomal layer, which diminishes the ability of spermatozoa to penetrate the zona pellucida (Yanagimachi, 1994). Some studies have suggested that vitamin E protects against LPO caused by ROS in bull and boar (Goovaerts et al., 2006; Breininger et al., 2005). In this study the groups treated with vitamin $E$ had larger percentages of sperm with intact acrosome membranes compared to the control group. In addition, L-Cysteine has the aptitude to rapidly pass into the cells, where it is altered to taurine. The taurine is united with fatty acids in membrane and altered into acyl-taurine, improving the surfactant properties and osmoregulation of the spermatozoa membrane (Esteves et al., 2007; Vazquez and Roldan, 1997).

The percentage of spermatozoa with high viability and increased DNA integrity in both of crossbred bulls were found when $7.5 \mathrm{mmol}$ of L-cysteine and $4.8 \mathrm{mmol}$ of vitamin $\mathrm{E}$ were added in freezing diluent $(P<0.05)$ compare to control group. Similarly, high MMP was observed when the freezing diluent treated with $7.5 \mathrm{mmol}$ of L-cysteine and $4.8 \mathrm{mmol}$ of vitamin $\mathrm{E}$ as compare to control group $(P$ $<0.05)$ followed by the other treated groups as shown in Table I, Figures 1 and 2. In this study the DNA integrity of freeze-thawed spermatozoa was significantly higher $(P<$ 0.05 ) in groups L-c-2 and vit-E-3 in both types of crossbred bulls. Cryopreservation method was found to damage the DNA integrity of buffalo spermatozoa, which affects the sperms functional credits and successful fetal development (Kumar et al., 2011) and, can also decrease the antioxidant potential of sperm. Antioxidants contribute in protecting DNA integrity during freeze-thawing (Bucak et al., 2010) by decreasing oxidative stress. Freeze-thawing induces adverse events such as ROS production and apoptosis- like changes; these events disturb the packaging of the sperm chromatin, in result a loss of DNA integrity (Topraggaleh et al., 2014). L-cysteine is sulfur-containing amino acids 
that are naturally found in seminal plasma and sperm nucleic acid. L-cysteine preserves DNA integrity and acts as an antioxidant directly and /or indirectly to defend cells against ROS (El-Sheshtawy et al., 2008; O'Flaherty et al., 1997), in agreement with the findings of the study. As vitamin $\mathrm{E}$ is a known inhibitor of LPO in cell membranes and acts as scavenger of ROS, thereby reducing oxidative damage during freeze-thawing of bull semen (Saacke and White, 1972).

Cryopreservation induced structural damages in mitochondria which altered the biochemical processes involved in ATP production, ultimately resulting in reduced sperm viability and motility (Figueroa et al., 2017). Mitochondria membrane is the key site of ROS production due to oxidative phosphorylation (Thuwanut et al., 2011). Kadirvel et al. (2009) found a negative relationship between mitochondrial membrane activity and ROS in freeze-thawed buffalo spermatozoa. Direct correlation exists among the MMP, sperm motility and fertilization capacity of freeuze-thawed spermatozoa. This relationship confirmed that cessation or activation of motility and successful fertilization depends on the availability of ATP in the spermatozoa (Fraser and Strzezek, 2007). The significant growth in MMP of freeze-thawed spermatozoa supplemented with L-cysteine and vitamin E could be due to the high antioxidant potential of L-cysteine and vitamin E to eliminate intracellular ROS and afterward protect mitochondria membrane activity.

The percentage of viable spermatozoa was significantly higher $(P<0.05)$ in groups L-cysteine -2 and vitamin-E-3 compared to control group. Spermatozoa viability and motility are the most essential requirements for fertile spermatozoa (Hossain et al., 2012). Freeze-thawing cycle results in substantial alterations in spermatozoa water content, creating considerable mechanical stress on the membrane and reducing spermatozoa viability (Hammerstedt et al., 1990). The addition of L-cysteine (7.5 $\mathrm{mmol}$ ) to tris-citric acid diluent was found to improvement the percentage of viable ovine spermatozoa (Bucak et al., 2008). Under field conditions, decrease in viable spermatozoa after freeze-thawing significantly reduces the fertility of bovine semen (Andrabi et al., 2006). In similar studies on ovine semen the addition of L-cysteine to semen extender resulted in higher percentage of live spermatozoa in association with increased catalase activity (Thomas et al., 1998; El-Sheshtawy et al., 2008). Our results show that vitamin E exhibits cryo-protective effects through its ability to reduce ROS accumulation. Our findings agree with several studies in which the addition of vitamin $\mathrm{E}$ to diluents enhanced the rate of motility and viability of spermatozoa (O’Flaherty et al., 1997; Hafez, 2004).

\section{CONCLUSIONS}

Addition of L-cysteine or vitamin E supplements at concentrations of 7.5 and $4.8 \mathrm{mmol}$ to semen diluents respectively, providing more strength to MMP and afterward elevated the spermatozoa freeze-thawed motility parameters in both crossbred bulls compared with control. In addition our study confirmed that adding $7.5 \mathrm{mmol}$ L-cysteine and $4.8 \mathrm{mmol}$ of vitamin $\mathrm{E}$ in freezing diluents enhanced sperm membrane functionality and DNA integrity. Therefore, these supplements can be suggested as an additional component for freezing diluent while in semen preservation of crossbred bulls. Further studies are recommended, to assess in vivo and in vitro fertility rates of freeze-thawed crossbred semen preserved with L-cysteine and vitamin $E$.

\section{ACKNOWLEDGEMENT}

We would like to thank the native English speaking scientists of Elixigen Company (Huntington Beach, California) for editing our manuscript.

\section{Funding}

This work is supported by The National Key Research and Development Program of China (2018YFD0501700), Key Research and Development Program of Anhui Province (1704a07020079) and Anhui Province Modern Agriculture Industry (Cattle, Goat and Sheep) Technology System (AHCYJSTX-07).

\section{Statement conflicts of interest}

The authors have declared no competing interest.

\section{REFERENCES}

Almbro, M., Damian, K. and Leigh, W., 2011. Effects of vitamin $\mathrm{E}$ and beta-carotene on sperm competitiveness. Ecol. Lett., 14: 891-895. https:// doi.org/10.1111/j.1461-0248.2011.01653.x

Aminipour, H., Tahmasbiand, A.M. and Naserain, A.A., 2013. The influence of vitamin $\mathrm{E}$ on semen characteristics of Ghezel rams in during cooling and frozen process. Eur. J. Zool., Res., 2: 94-99.

Amirat-Briand, L., Bencharif, D., Vera-Munoz, O., Bel Hadj Ali, H., Destrumelle, S., Desherces, S., Schmidt, E., Anton, M. and Tainturier, D., 2009. Effect of glutamine on post-thaw motility 
of bull spermatozoa after association with LDL (low density lipoproteins) extender: Preliminary results. Theriogenology, 71: 1209-1214. https://doi. org/10.1016/j.theriogenology.2008.10.002

Andrabi, S.M.H., Siddique, M., Ullah, N. and Khan, A., 2006. Effect of reducing sperm number per insemination dose on fertility of cryopreserved buffalo bull semen. Pak. Vet. J., 26: 17-19.

Andrade, A.F.C., Arruda, R.P., Celeghini, E.C.C., Nascimento, J., Martins, S.M.M.K., Raphael, C.F. and Moretti, A.S., 2007. Fluorescent stain method for the simultaneous determination of mitochondrial potential and integrity of plasma and acrosomal membranes in boar sperm. Reprod. Dom. Anim., 42: $\quad 190-194 . \quad$ https://doi.org/10.1111/j.14390531.2006.00751.x

Armstrong, J.S., Rajasekaran, M., Chamulitrat, W., Gatti, P., Hellstrom, W.J. and Sikka, S.C., 1999. Characterization of reactive oxygen species induced effects on human spermatozoa movement and energy metabolism. Free Radic. Biol Med., 26: 869-880. https://doi.org/10.1016/S0891-5849(98)00275-5

Beheshti, R., Asadi, A., Eshratkhah, B., GhaleKandi, J.G. and Ghorban, A., 2011. The Effect of cysteine on post-thawed buffalo bull (Bubalus bubalis) sperm parameters. Adv. environ. Biol., 5: 1260-1263.

Bitew, M. and Prasad, S., 2011. Study on major reproductive health problems in indigenous and cross breed cows in and around Bedelle. J. Anim. Vet. Adv., 10: 723-727. https://doi.org/10.3923/ javaa.2011.723.727

Breininger, E., Beorlegui, N.B., O'Flaherty, C.M. and Beconi, M.T., 2005. Alpha-tocopherol improves biochemical and dynamic parameters in cryopreserved boar semen. Theriogenology, 63: 2126-2135. https://doi.org/10.1016/j. theriogenology.2004.08.016

Bucak, M., Baspinar, N., Tuncer, P., Coyan, K., Sarızkan, S., Akalın, P., Buyukleblebici, S. and Kucukgunay, S., 2012. Effects of curcumin and dithioerythritol on frozen-thawed bovine semen. Andrologia, 44: 102-109. https://doi.org/10.1111/ j.1439-0272.2010.01146.x

Bucak, M.N., Atessahin, A. and Yüce, A., 2008. Effect of anti-oxidants and oxidative stress parameters on ram semen after the freeze-thawing process. Small Rumin. Res., 75: 128-134. https://doi.org/10.1016/j. smallrumres.2007.09.002

Bucak, M.N., Tuncer, P.B., Sarıözkan, S., Başpınar, N., Taşpınar, M., Çoyan, K., Bilgili, A., Akalın, P.P., Büyükleblebici, S. and Aydos, S., 2010. Effects of antioxidants on post-thawed bovine sperm and oxidative stress parameters: Antioxidants protect DNA integrity against cryodamage. Cryobiology, 61: 248-253. https://doi.org/10.1016/j. cryobiol.2010.09.001

Bucak, M.N., Tuncer, P.B., Sarızkan, S. and Ulutas, P.A., 2009. Comparison of the effects of glutamine and an amino acid solution on post-thawed ram sperm parameters, lipid peroxidation and anti-oxidant activities. Small Rumin. Res., 81: 13-17. https://doi. org/10.1016/j.smallrumres.2008.10.003

Dirami, T., Rode, B., Jollivet, M., Da silva, N., Escalier, D., Gaitch, N., Norez, C., Tuffery, P., Wolf, J.P., Becq, F., Ray, P.F., Dulioust, E., Gacon, G., Bienvenu, T. and Toure, A., 2013. Missense mutations in SLC26A8, encoding a sperm-specific activator of CFTR. Are associated with human asthenozoospermia. Am. J. Hum. Genet., 92: 760-766. https://doi.org/10.1016/j. ajhg.2013.03.016

El-Sheshtawy, R.I., El-Sisy, G.A. and El-Nattat, W.S., 2008. Use of selected amino acids to improves buffalo bull semen cryopreservation. Glob. Vet., 2: 146-150.

Esteves, S.C., Sharma, R.K., Thomas Jr, A.J. and Agarwal, A., 2007. Evaluation of acrosomal status and sperm viability in fresh and cryopreserved specimens by the use of fluorescent of peanut Agglutinin Lectin in conjunction with hypo-osmotic swelling test. Int. Braz. J. Urol., 33: 364-376. https://doi.org/10.1590/ S1677-55382007000300009

Evenson, D.P., Larson, K.L. and Jost, L.K., 2002. Sperm chromatin structure assay: its clinical use for detecting sperm DNA fragmentation in male infertility and comparisons with other techniques. J. Androl., 23: 25-43. https://doi.org/10.1002/j.1939-4640.2002. tb02599.x

Figueroa, Ea., Valdebenito, In., Zepeda, A.B., Figueroa, C.A., Dumorn, K., Castillo, R.L. and Farias, J.G., 2017. Effects of cryopreservation on mitochondria of fish spermatozoa. Rev. Aquacult., 9: 76-87. https://doi.org/10.1111/raq.12105

Fraser, L. and Strzezek, J., 2007. Effect of different procedures of ejaculate collection, extenders and packages on DNA integrity of boar spermatozoa following freezing-thawing. Anim. Reprod. Sci., 99: 317-329. https://doi.org/10.1016/j. anireprosci.2006.06.003

Gnoth, C., Godehardt, E., Frank-herrmann, P., Friol, K., Tigges, J. and Freundl, G., 2005. Definition and prevalence of subfertility and infertility. Hum. Reprod., 20: 1144-1147. https://doi.org/10.1093/ 
humrep/deh870

Goovaerts, I.G.F., Hoflack, G.G., Van Soom, A., Dewulf, J., Nichi, A. and de Kruif, A., 2006. Evaluation of epididymal semen quality using the Hamilton-Thorne analyser indicates variation between the two caudae epididymides of the same bull. Theriogenology, 66: 323-330. https://doi. org/10.1016/j.theriogenology.2005.11.018

Gulia, S., Sarkar, M., Kumar, V., Meyer, H.H.D. and Prakash, B.S., 2010. Divergent development of testosterone secretion in male zebu (Bos. indicus) and crossbred cattle (Bos. indicus x Bos. taurus) and buffaloes (Bubalus bubalis) during growth. Trop. Anim. Hlth. Prod., 42: 1143-1148. https://doi. org/10.1007/s11250-010-9538-x

Hafez, E.S.E., 2004. Anatomia da reprodução masculina. In: Reprodução animal (eds. E.S.E. Hafez and B. Hafez). Manole São Paulo. pp. 3-12.

Hammerstedt, R.H., Graham, J.K. and Nolan, J.P., 1990. Cryopreservation of mammalian sperm what we ask them to survive. J. Androl., 11: 73-88.

Hossain, M.E., Khatun, M.M., Islam, M.M. and Miazi, F., 2012. Semen characteristics of breeding bulls. Bangladesh J. Anim. Sci., 1: 1-5. https://doi. org/10.3329/bjas.v41i1.11968

Jeong, Y.J., Kim, M.K., Song, H.J., Kang, E.J., Ock, S.A., Kumar, B.M., Balasubramanian, S. and Rho, G.J., 2009. Effect of alpha-tocopherol supplementation during boar semen cryopreservation on sperm characteristics and expression of apoptosis related genes. Cryobiology, 58: 181-189. https://doi. org/10.1016/j.cryobiol.2008.12.004

Kadirvel, G., Kumar, S. and Kumaresan, A., 2009. Lipid peroxidation, mitochondrial membrane potential and DNA integrity of spermatozoa in relation to intracellular reactive oxygen species in liquid and frozen-thawed buffalo semen. Anim. Reprod. Sci., 114: 125-134. https://doi.org/10.1016/j. anireprosci.2008.10.002

Kaeoket, K., Chanapiwat, P., Tummaruk, P. and Techakumphu, M., 2010. Supplemental effect of varying L- cysteine concentrations on the quality of cryopreserved boar semen. Asian J. Androl., 12: 760-765. https://doi.org/10.1038/aja.2010.48

Keskes-Ammar, L., Feki-Chakroun, N., Rebai, T., Sahnoun, Z., Ghozzi, H. and Hammami, S., 2003. Sperm oxidative stress and the effect of an oral vitamin $\mathrm{E}$ and selenium supplement on semen quality in infertile men. Arch. Androl., 49: 83-94. https://doi.org/10.1080/713828100

Kovacs, A. and Foote, R.H., 1992. Viability and acrosome staining of bull, boar and rabbit spermatozoa. Biotech. Histochem., 67: 119-124. https://doi. org/10.3109/10520299209110020

Kulaksiz, R. and Daskin, A., 2010. In vitro evaluation of Saanen buck semen frozen in different extenders supplemented with various antioxidants. Ankara Üniv. Vet. Fak. Derg., 57: 151-156. https://doi. org/10.1501/Vetfak_0000002369

Kumar, R., Mohanarao, G.J. and Arvind Atreja, S.K., 2011. Freeze-thaw induced genotoxicity in buffalo (Bubalus bubalis) spermatozoa in relation to total antioxidant status. Mol. Biol. Rep., 38: 1499-1506. https://doi.org/10.1007/s11033-010-0257-1

Leite, T.G., Filho, V.R.D.V., Arruda, R.P.D., André Furugen, Cesar de Andrade, Emerick, L.L. and Zaffalon, F.G., 2010. Effects of extender and equilibration time on post-thaw motility and membrane integrity of cryopreserved gyr bull semen evaluated by casa and flow cytometry. Anim. Reprod. Sci., 120: 0-38. https://doi.org/10.1016/j. anireprosci.2010.04.005

Lenzi, A., Picardo, M., Gandini, L. and Dondero, F., 1996. Lipids of the sperm plasma membrane: from polyunsaturated fatty acids considered as markers of sperm function to possible scavenger therapy. Hum. Reprod. Update, 2: 246-256. https://doi. org/10.1093/humupd/2.3.246

Li, Z., Lin, Q., Liu, R., Xiao, W. and Liu, W., 2010. Protective effects of ascorbate and catalase on human spermatozoa during cryopreservation. $J$. Androl., 31: 437-444. https://doi.org/10.2164/ jandrol.109.007849

Mandal, D.K., Tyagi, S. and Kumar, M., 2008. Sexual behavior in Holstein Friesian x Sahiwal crossbred bulls. Indian J. Vet. Sci., 85: 636-639.

Mandal, D.K. and Tyagi, S., 2004. Pre-copulatory behavior of Sahiwal bulls during semen collection and effects of age and season on their sexual performance. Indian J. Dairy Sci., 57: 334-338.

Meister, A. and Anderssson, M.E., 1983. Glutathione. Annu. Rev. Biochem., 52: 711-760. https://doi. org/10.1146/annurev.bi.52.070183.003431

Minervini, F., Guastamacchia, R., Pizzi, F., Dell'Aquila, M. and Barile, V., 2013. Assessment of different functional parameters of frozen-thawed buffalo spermatozoa by using cytofluorimetric determinations. Reprod. Domest. Anim., 48: 317-324. https://doi.org/10.1111/j.1439-0531.2012.02152.x

Motemani, M., Chamani, M. and Sharafi, M., 2017. Alpha-tocopherol improves frozen-thawed sperm quality by reducing hydrogen peroxide during 
cryopreservation of bull semen. Span. J. agric. Res., 15: e0401. https://doi.org/10.5424/sjar/20171519761

Mukhopadhyay, C.S., Gupta, A.K., Yadav, B.R., Khate, K., Raina, V.S. and Mohanty, T.K., 2010. Subfertility in males an important cause of bull disposal in bovines. Asian-Austral. J. Anim. Sci., 23: 450-455. https://doi.org/10.5713/ajas.2010.90298

Nichi, M., Bols, P.E.G., Zuge, R.M., Barnabe, V.H., Goovaerts, I.G.F., Barnabe, R.C. and Cortada, C.N.M., 2006. Seasonal variation in semen quality in Bos indicus and Bos taurus bulls raised under tropical conditions. Theriogenology, 66: 822-828. https:// doi.org/10.1016/j.theriogenology.2006.01.056

O'Flaherty, C., Beconi, M. and Beorlegui, N., 1997. Effect of natural antioxidants, superoxide dismutase and hydrogen peroxide on capacitation of frozen/ thawed bull sperm. Andrologia, 29: 269-275. https:// doi.org/10.1111/j.1439-0272.1997.tb00481.x

Pons-Rejraji, H., Sion, B. and Saez, F., 2009. Role of reactive oxygen species (ROS) on human spermatozoa and male infertility. Gynecol. Obstet. Fertil., 37: 529-535.

Saacke, R.G. and White, J.M., 1972. Semen quality tests and their relationship to fertility. Technical Conference on Artificial Insemination and Reproduction. pp. 22-27.

Sariözkan, S., Bucak, M.N., Tuncer, B.P., Ulutaş, P.A. and Bilgen, A., 2009. The influence of cysteine and taurine on microscopic-oxidative stress parameters and fertilizing ability of bull semen following cryopreservation. Cryobiology, 58: 1334-1338. https://doi.org/10.1016/j.cryobiol.2008.11.006

Sattar, A. and Mirza, R.H., 2009. Haematological parameters in exotic cows during gestation and lactation under subtropical conditions. Pak. Vet. J., 29: 129-132.

Silva, S.V., Soares, A.T., Batista, A.M., Almeida, F.C., Nunes, J.F., Peixoto, C.A. and Guerra, M.M., 2013. Vitamin E (Trolox) addition to Tris-egg yolk extender preserves ram spermatozoon structure and kinematics after cryopreservation. Anim. Reprod. Sci., 137: 37-44. https://doi.org/10.1016/j. anireprosci.2012.12.002

Sudheer, S. and Xavier, C.J., 2000. Disposal pattern of breeding bulls in Kerala. Indian J. Anim. Reprod., 211: 72-73.

Surai, P.F., Brillard, J.P., Speake, B.K., Blesbois, E., Seigneurin, F., Sparks, N.H., 2000. Phospholipids fatty acid composition, vitamin $\mathrm{E}$ content and susceptibility to lipid peroxidation ofduck spermatozoa. Theriogenology, 53: 1025- 1039. https://doi.org/10.1016/S0093-691X(00)00249-1

Tartaglione, C.M. and Ritta, M.N., 2004. Prognostic value of spermatological parameters as predictors of in vitro fertility of frozen-thawed bull semen. Theriogenology, 62: 1245-1252. https://doi. org/10.1016/j.theriogenology.2004.01.012

Thippeswamy, V.B., Layek, S.S., Kumaresan, A., Mohanty, T.K., Gupta, A.K., Chakravarty, A.K., Manimaran, A. and Prasad, S., 2014. Effects of pedigree and exotic genetic inheritance on semen production traits of dairy bulls. Asia. Pac. J. Reprod., 3: 13-17. https://doi.org/10.1016/S23050500(13)60178-5

Thomas, C.A., Garner, D.L., Dejarnette, J.M. and Marshall, C.E., 1998. Effect of cryopreservation of bovine sperm organelle function and viability as determined by flow cytometry. Biol. Reprod., 58: 786793. https://doi.org/10.1095/biolreprod58.3.786

Thuwanut, P., Chatdarong, K., Bergqvist, A.S., Soderquist, L., Thiangtum, K., Tongthainan, D. and Axner, E., 2011. The effects of antioxidants on semen traits and in vitro fertilizing ability of sperm from the flat-headed cat (Prionailurus planiceps). Theriogenology, 76: 115-125. https:// doi.org/10.1016/j.theriogenology.2011.01.024

Thuwanut, P., Chatdarong, K., Techakumphu, M. and Axner, E., 2008. The effect of antioxidants on motility, viability, acrosome integrity and DNA integrity of frozen-thawed epididymal cat spermatozoa. Theriogenology, 70: 233-240. https:// doi.org/10.1016/j.theriogenology.2008.04.005

Topraggaleh, T.R., Shahverdi, A., Rastegarnia, A., Ebrahimi, B., Shafiepour, V., Sharbatoghli, M., Esmaeili, V. and Janzamin, E., 2014. Effect of cysteine and glutamine added to extender on postthaw sperm functional parameters of buffalo bull. Andrologia, 46: 777-783. https://doi.org/10.1111/ and.12148

Trachootham, D., Alexandre, J. and Huang, P., 2009. Targeting cancer cells by ROS-mediated mechanisms: a radical therapeutic approach? Nat. Rev. Drug Discov., 8: 579-591. https://doi. org/10.1038/nrd2803

Tuncer, P.B., Bucak, M.N., Buyukleblebici, S., Sarıozkan, S., Yeni, D., Eken, A., Akalın, P.P., Kinet, H., Avdatek, F. and Fidan, A.F., 2010. The effect of cysteine and glutathione on sperm and oxidative stress parameters of post-thawed bull semen. Cryobiology, 61: 303-307. https://doi.org/10.1016/j. cryobiol.2010.09.009 
Vazquez, J.M. and Roldan, E.R., 1997. Phospholipid metabolism in boar spermatozoa and role of diacylglycerol species in the de novo formation of phosphatidylcholine. Mol. Reprod. Dev., 47: 105-112. https://doi.org/10.1002/(SICI)10982795(199705)47:1<105::AID-MRD14>3.0.CO;2-0

Yanagimachi, R., 1994. Mammalian fertilization. In: The physiology of reproduction (eds. E. Knobil and J.D. Neill). Raven Press, New York. pp. 189-317.

Yousef, M.I.,Abdallah, G.A. and Kamel, K.I., 2003. Effect of ascorbic acid and vitamin E supplementation on semen quality and biochemical parameters of male rabbits. Anim. Reprod. Sci., 76: 99-111. https://doi. org/10.1016/S0378-4320(02)00226-9 